\title{
Penerapan Algoritma C4.5 Dalam Mengukur Kepuasan Pengunjung Terhadap Fasilitas di Taman Margasatwa Jakarta
}

\author{
Hendri $^{1}$, Dony Oscar ${ }^{2}$ \\ ${ }^{1}$ STMIK Nusa Mandiri, \\ ${ }^{2}$ Universitas Bina Sarana Informatika \\ e-mail: ${ }^{1}$ hendri.hed@nusamandiri.ac.id, ${ }^{2}$ Dony.dor@bsi.ac.id

\begin{tabular}{ccc}
\hline Diterima & Direvisi & Disetujui \\
$21-04-2021$ & $01-06-2021$ & $09-06-2021$ \\
\hline
\end{tabular}

\begin{abstract}
Abstrak - Kepuasan pengunjung adalah suatu tingkatan dimana kebutuhan ,keinginan dan harapan dari pengunjung dapat terpenuhi yang mengakibatkan pengunjung akan datang lagi (Zelmiati Zelmiati, Waryono Waryono, 2017). Taman margasatwa adalah salah satu objek wisata binatang yang paling banyak diminati masyarakat. Banyak hal yang harus diperhatikan dalam mengembangkan suatu objek wisata yaitu dengan memberikan sesuatu yang sesuai dengan yang dibutuhkan dan kenginan calon pengunjung. Berdasarkan fenomena tersebut peneliti menemukan bahwa jumlah pengunjung yang terus meningkat masih ada masalah yang dihadapi diTaman Margasatwa yaitu dari segi fasilitas wisata, Penelitian ini bertujuan untuk memberi rekomendasi kepuasan pengunjung taman taman margasatwa dengan menggunakan teknik datamining penerapan datamining C4.5. Sumber data diperoleh dari penyebaran kuesioner kepada pengnjung yang pernah berkunjung ke taman margasatwa kepada 35 orang. Atribut yang digunakan sebagai parameter penilaian kepuasan pengunjung antara lain: Paling Diminati,Fasilitas Semuah,Tempat parkir, Keamanan, dan Kebersihan . Hasil pengolahan metode C4.5 dengan menggunakan Pohon keputusan adalah model prediksi menggunakan struktur pohon atau struktur berhirarki.
\end{abstract}

Kata Kunci: Kepuasan, Metode C4.5, Taman Margasatwa

\begin{abstract}
Abstrak - Visitor satisfaction is a level where the needs, wants and expectations of visitors can be met which results in visitors coming again (Zelmiati Zelmiati, Waryono Waryono, 2017). Wildlife parks are one of the most popular animal attractions in the community. There are many things that must be considered in developing a tourist attraction, namely by providing something that is in accordance with the needs and desires of potential visitors. Based on this phenomenon, the researchers found that the number of visitors who continue to increase there are still problems faced at the Wildlife Park, namely in terms of tourist facilities. Sources of data were obtained from distributing questionnaires to 35 people who had visited the wildlife park. The attributes used as parameters for assessing visitor satisfaction include: Most Interested, All Facilities, Parking, Security, and Cleanliness. The result of processing the C4.5 method using a decision tree is a predictive model using a tree structure or a hierarchical structure.
\end{abstract}

Keywords: Satisfaction, Method C4.5, Wildlife Park

\section{PENDAHULUAN}

Taman margasatwa adalah salah satu objek wisata binatang yang paling banyak diminati masyarakat. Banyak hal yang harus diperhatikan dalam mengembangkan suatu objek wisata yaitu dengan memberikan sesuatu yang sesuai dengan yang dibutuhkan dan kenginan calon pengunjung.Antusiasme pengunjung terhadap suatu objek wisata berdampak pada tingginya jumlah pengunjung.Tinggginya jumlah pengunjung dan dalam hal tersebuat mebuat kebun biantang menjadi salah satu destinasi wisata yang sangat diminati dijakarta sehingga mengharuskan pihak pengelola untuk memperhatikan kepuasan pengunjung

Kenaikan jumlah pengunjung mengidentifikasikan adanya kepuasaan berkunjung. Sebuah tempat yang dapat memuaskan pengunjung meliliki citra yang baik dari pengunjung namun hal tersebut bertolak belakang dengan opini-opini mengenai Taman Margaswatwa mengenai fasilitas diTaman Margastwa yang dianggap masih kurang.kondisi kandang yang kurang terawat dan tempat parkir yang membuat pengunjung merasa kurang puas (Marhanah \& Wahadi, 2016)

Kepuasan pengunjung adalah suatu tingkatan dimana kebutuhan ,keinginan dan harapan dari pengunjung dapat terpenuhi yang mengakibatkan pengunjung akan datang lagi (Zelmiati Zelmiati, Waryono Waryono, 2017). Banyak faktor yang mempengaruhi kepuasaan pengunjung antara lain : faktor kebersihan,fasilitas,tempat parkir,keamanan yang ada pada tempat objek wisata. 
Berdasarkan fenomena tersebut peneliti menemukan bahwa jumlah pengunjung yang terus meningkat masih ada masalah yang dihadapi diTaman Margasatwa yaitu dari segi fasilitas wisata,namun,pada saat ini pihak taman margastwa sedang melakukan peningkatan terhadap fasilitas yang diberikan kepada pengunjung dengan tujuan dapat mendapatkan kepuasan pengunjung.Berkait dengan hasil yang didapat kan peneliti.peneliti tertarik untuk melakukan penelitian lebih lanjut mengenai pengaruh fasilitas terhadap kepuasan pengunjung di Taman Margasatwa.Adapun judul dari penelitian yang oleh peneliti adalah "Penerapan Data Mining Menggunakan Metode Algoritma c4.5 Untuk Tingkat kepuasan Pengunjung Terhadap Fasilitas DiTaman Margasatwa (Marhanah \& Wahadi, 2016).

\section{KAJIAN LITERATUR}

\section{A. Data Mining}

Data mining adalah kegiatan yang meliputi pengumpulan, pemakaian data historis yang menemukan keteraturan ini yaitu proses pencarian informasi yang tidak diketahui sebelumnya dari sekumpulan data besar (Junia et al., 2021). Menurut yuli mardi Data mining adalah proses yang menggunakan teknik statistik, matematika, kecerdasan buatan, dan machine learning untuk mengekstraksi dan mengidentifikasi informasi yang bermanfaat danpengetahuan yang terkait dari berbagai database besar (Mardi, 2017). Menurut para ahli data mining adalah proses menemukan pola pengetahuan dari data dalam jumlah besar. Sumber data dapat berupa database, data warehouses, Website, repositori, atau data yang disimpan ke sistem secara dinamis.(Han et al., 2014)

\section{B. Pohon Keputusan}

Pohon keputusan dapat diartikan suatu cara untuk memprediksi atau mengklarifikasi yang sangat kuat. Pohon keputusan dapat membagi kumpulan data yang besar menjadi himpunan-himpunan record yang lebih kecil dengan menerapkan serangkaian aturan keputusan (Novianti et al., 2016).

Pohon keputusan adalah kemampuannya untuk mem-break down proses pengambilan keputusan akan lebih menginterpretasikan solusi dari permasalahan (Syarif Mayron Turnip, 2018). Pohon keputusan juga berguna untuk mengeksplorasi data, menemukan hubugan tersembunyi antara sejumlah calon variabel input dengan sebuah variabel input dengan sebuah variabel target (Firmansyah \& Aufany, 2016).

\section{Algoritma C4.5}

Algortima C4.5 merupakan kelompok algortima pohon keputusan (Decision Tree).
Algoritma ini mempunyai input berupa training samples dan samples. Training samples berupa data yang akan digunakan untuk membangun sebuah tree yang telah diuji kebenarannya (Junia et al., 2021).

\section{METODE PENELITIAN}

Metodologi adalah suatu cara yang digunakan dalam mendapatkan berbagai data yang akan diperoses menjadi sebuah informasi yang lebih akurat sesuai dengan permasalahan yang akan diteliti. Metodologi penelitian juga dilakukan dengan mendeskripsikan masalah untuk memudahkan dalam memahami tahapan penelitian

\section{A. Pengumpulan Data}

Berikut adalah cara yang dilakukan dalam pengumpulan data sebagai berikut :

\section{Pengumpulan Data Primer}

Dilakukan untuk mendapatkan informasi yang digunakn peneliti dalam pembuatan penelitian agar hasil yang didapatkan akurat. Penelitian dilakukan dengan cara kuesioner dengan menggunakan google formulir

2. Pengumpulan data sekunder

Pengumpulan data sekunder diperoleh melalui jurnal,makalah,laporan dll

\section{B. Populasi}

Populasi adalah wilayah generalisasi yang terdiri atas obyek/subyek yang mempunyai kualitas dan karakteristik tertentu yang ditetapkan oleh peneliti untuk dipelajari dan kemudian ditarik(Vogt, 2015). Populasi dalam penelitian ini adalah para responden yang pernah berkunjung ke Taman Margasatwa.

Dalam penelitian ini pengambilan sampel adalah menyebar kuesioner kepada masyarakat yang pernah berkunjung ke Taman Margasatwa. Pada penelitian ini jumlah populasi tidak diketahui sehingga sampel yang diambil dari kuesioner yang di isi oleh responden sebanyak 35 respoden agar mewakili populasi tidak secara keseluruhan.

\section{Metode Analis Data}

Untuk menentukan Kepuasan Pengunjung

Terhadap Fasilitas Taman Margasatwa Menggunakan Metode Algoritma C4.5 maka data yang akan digunakan dan di analisa data kuesioner responden yang pernah ke taman margasatwa dimana ddiperoleh dari pengisian kuesioner dari pengunjung. Untuk menentukan kepuasan pengunjung yaitu dibedakan menjadi dua clas yaitu Puas dan Tidak Puas. 


\section{Menentukan Atribut}

Tahap utama pada penelitian ini adalah menentukan jenis atribut yang nantinya akan dijadikan proses dalam menentukan kepuasan pengunjung dalam penelitian jumlah kriteria yang disediakan sebanyak 5 kriteria yaitu Paling Diminati, Fasilitas Semua, Tempat Parkir, Keamanan, Kebersihan

\section{E. Algoritma C4.5}

Entropy adalah ukuran dari teori informasi yang dapat mengetahui karakteristik dari impuryt dan homogenity dari kumpulan(Arifin \& Fitrianah, 2018), . Dari nilai Entropy tersebut kemudian dihitung nilai information gain masing-masing atribut. Penghitungan nilai Entropy digunakan rumus seperti dalam Persamaan

Entropy $(S)=\sum n i=0-p i * \log 2(p i)$

Berikut keterangannya :

$\mathrm{S}$ : Himpunan kasus

$\mathrm{N}:$ Jumlah partisi

Pi : Jumlah kasus pada partisi ke-i"

Information Gain adalah informasi yang didapatkan dari perubahan entropy pada suatu kumpulan data, baik melalui observasi atau bisa juga disimpulkan dengan cara melakukan partisipasi terhadap suatu set data(Arifin \& Fitrianah, 2018).

$\operatorname{GAIN}(S, A)=\operatorname{Entropy}(S)-\Sigma n i=1-|S i| *$

Entropy $(\mathrm{Si})$

Berikut keterangannya :

$\mathrm{S}$ : Himpunan kasus

$\mathrm{N}$ : Jumlah partisi atribut A

|Si| : Jumlah kasus pada partisi ke-i

$|\mathrm{S}|$ : Jumlah kasus da

\section{HASIL DAN PEMBAHASAN}

Data yang peneliti gunakan dalam penelitian ini adalah data kuesioner. Data diperoleh dari pembagian kuesioner sebanyak 35 responden. Data yang dikumpulkan yaitu data kuesioner yang dibagikan kepada masyarakat yang pernah berkunjung ke Taman Margasatwa. Penyebaran kuesioner dimulai pada bulan April 2020. Untuk mempermudah pengisian dan pengelolahan data ,maka dibuatkanlah kriteria dan alternatif pada kepuasaan pengunjung kriteria yang digunakan dalam penelitian ini yaitu wisata yang paling diminati,fasilitas yang ada,tempat perkir,keamanaan,kebersihan

\section{Data Training}

Data traning adalah data yang digunakan untuk melakukan perhitungan menggunakan metode
Algoritma C4.5 berikut adalah tabel dari data training yang digunakan

Tabel 1. Data Training

\begin{tabular}{|c|c|c|c|c|c|c|}
\hline $\begin{array}{l}\mathrm{N} \\
\mathrm{o} .\end{array}$ & $\begin{array}{l}\text { Paling } \\
\text { Dinik } \\
\text { mati }\end{array}$ & $\begin{array}{l}\text { Fasilitas } \\
\text { Semua }\end{array}$ & $\begin{array}{l}\text { Tempat } \\
\text { Parkir }\end{array}$ & $\begin{array}{l}\text { Keam } \\
\text { anaan }\end{array}$ & $\begin{array}{l}\text { Keber } \\
\text { sihan }\end{array}$ & Hasil \\
\hline 1 & 4 & 3 & 3 & 2 & 2 & $\begin{array}{l}\text { Tidak } \\
\text { Puas }\end{array}$ \\
\hline 2 & 4 & 4 & 2 & 4 & 4 & Puas \\
\hline 3 & 3 & 4 & 2 & 3 & 3 & Puas \\
\hline 4 & 4 & 3 & 2 & 3 & 2 & puas \\
\hline 5 & 3 & 3 & 3 & 3 & 3 & puas \\
\hline 6 & 3 & 4 & 2 & 3 & 3 & puas \\
\hline 7 & 3 & 1 & 2 & 2 & 1 & $\begin{array}{l}\text { Tidak } \\
\text { Puas } \\
\end{array}$ \\
\hline 8 & 3 & 3 & 3 & 3 & 3 & Puas \\
\hline 9 & 3 & 3 & 3 & 3 & 4 & Puas \\
\hline 10 & 3 & 4 & 2 & 3 & 3 & Puas \\
\hline 11 & 3 & 3 & 3 & 3 & 3 & Puas \\
\hline 12 & 3 & 4 & 3 & 4 & 3 & puas \\
\hline 13 & 3 & 3 & 3 & 3 & 3 & Puas \\
\hline 14 & 3 & 3 & 3 & 4 & 4 & Puas \\
\hline 15 & 3 & 3 & 2 & 3 & 3 & $\begin{array}{l}\text { Tidak } \\
\text { Puas }\end{array}$ \\
\hline 16 & 3 & 4 & 3 & 4 & 4 & Puas \\
\hline 17 & 4 & 4 & 3 & 3 & 3 & Puas \\
\hline 18 & 3 & 2 & 2 & 1 & 2 & $\begin{array}{l}\text { Tidak } \\
\text { Puas } \\
\end{array}$ \\
\hline 19 & 4 & 4 & 3 & 3 & 3 & Puas \\
\hline 20 & 3 & 3 & 2 & 3 & 3 & $\begin{array}{l}\text { Tidak } \\
\text { Puas }\end{array}$ \\
\hline 21 & 3 & 4 & 2 & 4 & 4 & $\begin{array}{l}\text { Tidak } \\
\text { Puas } \\
\end{array}$ \\
\hline 22 & 3 & 3 & 3 & 3 & 3 & Puas \\
\hline 23 & 3 & 3 & 2 & 1 & 2 & $\begin{array}{l}\text { Tidak } \\
\text { Puas }\end{array}$ \\
\hline 24 & 3 & 3 & 2 & 3 & 4 & $\begin{array}{l}\text { Tidak } \\
\text { Puas } \\
\end{array}$ \\
\hline 25 & 3 & 3 & 3 & 3 & 3 & Puas \\
\hline 26 & 4 & 4 & 3 & 3 & 4 & Puas \\
\hline 27 & 4 & 4 & 3 & 4 & 4 & Puas \\
\hline 28 & 3 & 3 & 3 & 4 & 3 & Puas \\
\hline 29 & 3 & 3 & 2 & 3 & 2 & $\begin{array}{l}\text { Tidak } \\
\text { Puas } \\
\end{array}$ \\
\hline 30 & 4 & 3 & 3 & 3 & 4 & Puas \\
\hline 31 & 3 & 3 & 2 & 2 & 3 & $\begin{array}{l}\text { Tidak } \\
\text { Puas }\end{array}$ \\
\hline 32 & 3 & 3 & 3 & 3 & 3 & Puas \\
\hline 33 & 3 & 3 & 3 & 2 & 3 & $\begin{array}{l}\text { Tidak } \\
\text { Puas }\end{array}$ \\
\hline 34 & 3 & 4 & 3 & 4 & 3 & Puas \\
\hline 35 & 3 & 4 & 3 & 2 & 3 & $\begin{array}{l}\text { Tidak } \\
\text { Puas }\end{array}$ \\
\hline
\end{tabular}




\section{Data Testing}

Berdasarkan pada data training diatas, data yang diuji dengan menggunakan Data testing Algoritma C4.5 dalah seperti tabel dibawah ini

Tabel 2. Data Testing

\begin{tabular}{|c|c|c|c|c|c|c|}
\hline $\begin{array}{l}\text { No } \\
.\end{array}$ & $\begin{array}{l}\text { Paling } \\
\text { Dinikmati }\end{array}$ & $\begin{array}{l}\text { Fasilitas } \\
\text { Semua }\end{array}$ & $\begin{array}{l}\text { Tempat } \\
\text { Parkir }\end{array}$ & $\begin{array}{l}\text { Keama } \\
\text { naan }\end{array}$ & $\begin{array}{l}\text { Kebers } \\
\text { ihan }\end{array}$ & Hasil \\
\hline 1 & 4 & 3 & 3 & 2 & 2 & $\begin{array}{l}\text { Tidak } \\
\text { Puas }\end{array}$ \\
\hline 2 & 4 & 4 & 2 & 4 & 4 & Puas \\
\hline 3 & 3 & 4 & 2 & 3 & 3 & Puas \\
\hline 4 & 4 & 3 & 2 & 3 & 2 & puas \\
\hline 5 & 3 & 3 & 3 & 3 & 3 & puas \\
\hline 6 & 3 & 4 & 2 & 3 & 3 & puas \\
\hline 7 & 3 & 1 & 2 & 2 & 1 & $\begin{array}{l}\text { Tidak } \\
\text { Puas }\end{array}$ \\
\hline 8 & 3 & 3 & 3 & 3 & 3 & Puas \\
\hline 9 & 3 & 3 & 3 & 3 & 4 & Puas \\
\hline 10 & 3 & 4 & 2 & 3 & 3 & Puas \\
\hline 11 & 3 & 3 & 3 & 3 & 3 & Puas \\
\hline 12 & 3 & 4 & 3 & 4 & 3 & puas \\
\hline 13 & 3 & 3 & 3 & 3 & 3 & Puas \\
\hline 14 & 3 & 3 & 3 & 4 & 4 & Puas \\
\hline 15 & 3 & 3 & 2 & 3 & 3 & $\begin{array}{l}\text { Tidak } \\
\text { Puas }\end{array}$ \\
\hline 16 & 3 & 4 & 3 & 4 & 4 & Puas \\
\hline 17 & 4 & 4 & 3 & 3 & 3 & Puas \\
\hline 18 & 3 & 2 & 2 & 1 & 2 & $\begin{array}{l}\text { Tidak } \\
\text { Puas }\end{array}$ \\
\hline 19 & 4 & 4 & 3 & 3 & 3 & Puas \\
\hline 20 & 3 & 3 & 2 & 3 & 3 & $\begin{array}{l}\text { Tidak } \\
\text { Puas }\end{array}$ \\
\hline 21 & 3 & 4 & 2 & 4 & 4 & $\begin{array}{c}\text { Tidak } \\
\text { Puas } \\
\end{array}$ \\
\hline 22 & 3 & 3 & 3 & 3 & 3 & Puas \\
\hline 23 & 3 & 3 & 2 & 1 & 2 & $\begin{array}{l}\text { Tidak } \\
\text { Puas }\end{array}$ \\
\hline 24 & 3 & 3 & 2 & 3 & 4 & $\begin{array}{c}\text { Tidak } \\
\text { Puas }\end{array}$ \\
\hline 25 & 3 & 3 & 3 & 3 & 3 & Puas \\
\hline 26 & 4 & 4 & 3 & 3 & 4 & Puas \\
\hline 27 & 4 & 4 & 3 & 4 & 4 & Puas \\
\hline 28 & 3 & 3 & 3 & 4 & 3 & Puas \\
\hline 29 & 3 & 3 & 2 & 3 & 2 & $\begin{array}{l}\text { Tidak } \\
\text { Puas }\end{array}$ \\
\hline 30 & 4 & 3 & 3 & 3 & 4 & Puas \\
\hline
\end{tabular}

a. Perhitungan Entrophy \& Gain

Berikut ini adalah cara perhitungan entrophy total dan gain dari paling diminati yaitu sebagai berikut :

Tabel 3. Perhitungan Node 1

\begin{tabular}{|c|c|c|c|c|c|c|c|}
\hline $\begin{array}{l}\text { No } \\
\text { de }\end{array}$ & & \multicolumn{2}{|c|}{ Jumlah (S) } & $\begin{array}{l}\text { Pua } \\
\text { s( Si }\end{array}$ & $\begin{array}{l}\text { Tida } \\
\text { k ( Si }\end{array}$ & $\begin{array}{l}\text { Entrop } \\
\text { hy }\end{array}$ & Gain \\
\hline 1 & Total & & 30 & 21 & 9 & $\begin{array}{r}0,8812 \\
90899\end{array}$ & \\
\hline & $\begin{array}{l}\text { Paling } \\
\text { Dimina } \\
\text { ti }\end{array}$ & & & & & & $\begin{array}{r}0,0428 \\
56158\end{array}$ \\
\hline & & $\begin{array}{l}\text { Sangat } \\
\text { Setuju }\end{array}$ & 8 & 7 & 1 & $\begin{array}{r}0,5435 \\
64443\end{array}$ & \\
\hline & & Setuju & 22 & 14 & 8 & $\begin{array}{r}0,9456 \\
60305 \\
\end{array}$ & \\
\hline & & $\begin{array}{l}\text { Tidak } \\
\text { Setuju }\end{array}$ & 0 & 0 & 0 & 0 & \\
\hline & & $\begin{array}{l}\text { Sangat } \\
\text { Tidak } \\
\text { Setuju }\end{array}$ & 0 & 0 & 0 & 0 & \\
\hline & $\begin{array}{l}\text { Fasilita } \\
\text { s } \\
\text { Semua } \\
\text { h }\end{array}$ & & & & & & $\begin{array}{r}0,1893 \\
63821\end{array}$ \\
\hline & & $\begin{array}{l}\text { Sangat } \\
\text { Setuju }\end{array}$ & 11 & 10 & 1 & $\begin{array}{r}0,4394 \\
96987 \\
\end{array}$ & \\
\hline & & Setuju & 17 & 11 & 6 & $\begin{array}{r}0,9366 \\
67382 \\
\end{array}$ & \\
\hline & & $\begin{array}{l}\text { Tidak } \\
\text { Setuju }\end{array}$ & 1 & 0 & 1 & 0 & \\
\hline & & $\begin{array}{l}\text { Sangat } \\
\text { Tidak } \\
\text { Setuju }\end{array}$ & 1 & 0 & 1 & 0 & \\
\hline & $\begin{array}{l}\text { Tempat } \\
\text { Parkir }\end{array}$ & & & & & & $\begin{array}{r}0,2818 \\
59427\end{array}$ \\
\hline & & $\begin{array}{l}\text { Sangat } \\
\text { Setuju }\end{array}$ & 0 & 0 & 0 & 0 & \\
\hline & & Setuju & 17 & 16 & 1 & $\begin{array}{r}0,3227 \\
56959 \\
\end{array}$ & \\
\hline & & $\begin{array}{l}\text { Tidak } \\
\text { Setuju }\end{array}$ & 13 & 5 & 8 & $\begin{array}{r}0,9612 \\
36605\end{array}$ & \\
\hline & & $\begin{array}{l}\text { Sangat } \\
\text { Tidak } \\
\text { Setuju }\end{array}$ & 0 & 0 & 0 & 0 & \\
\hline & $\begin{array}{l}\text { Keama } \\
\text { naan }\end{array}$ & & & & & & $\begin{array}{r}0,2729 \\
9179 \\
\end{array}$ \\
\hline & & $\begin{array}{l}\text { Sangat } \\
\text { Setuju }\end{array}$ & 7 & 6 & 1 & $\begin{array}{r}0,5916 \\
72779 \\
\end{array}$ & \\
\hline & & Setuju & 19 & 15 & 4 & $\begin{array}{r}0,7424 \\
8757 \\
\end{array}$ & \\
\hline & & $\begin{array}{l}\text { Tidak } \\
\text { Setuju }\end{array}$ & 2 & 0 & 2 & 0 & \\
\hline & & $\begin{array}{l}\text { Sangat } \\
\text { Tidak } \\
\text { Setuju }\end{array}$ & 2 & 0 & 2 & 0 & \\
\hline & $\begin{array}{l}\text { Kebersi } \\
\text { haan }\end{array}$ & & & & & & $\begin{array}{r}0,2484 \\
53445 \\
\end{array}$ \\
\hline & & $\begin{array}{l}\text { Sangat } \\
\text { Setuju }\end{array}$ & 9 & 7 & 2 & $\begin{array}{r}0,7642 \\
04507\end{array}$ & \\
\hline & & Setuju & 15 & 13 & 2 & $\begin{array}{r}0,5665 \\
09507\end{array}$ & \\
\hline & & $\begin{array}{l}\text { Tidak } \\
\text { Setuju }\end{array}$ & 5 & 1 & 4 & $\begin{array}{r}0,7219 \\
28095\end{array}$ & \\
\hline & & $\begin{array}{l}\text { Sangat } \\
\text { Tidak } \\
\text { Setuju }\end{array}$ & 1 & 0 & 1 & 0 & \\
\hline
\end{tabular}

Baris total kolom Entophy pada Tabel 3 dihitung dengan rumus sebagai berikut :

Entrophy ( Total $)=\left(-\frac{21}{30} * \log 2\left(\left(\frac{21}{30}\right)\right)+\left(-\frac{9}{30}\right) * \log 2\left(\frac{9}{30}\right)\right)$

Entrophy $($ Total $)=0,881290899$

Sementara itu nilai Gain pada baris Paling Diminati dihitung dengan menggunakan rumus Gain Sebagai berikut :

Gain $($ Total,Paling Diminati $)=$ Entrophy $($ Total $)$

$\sum_{i=1}^{n} \frac{\text { cuaca }}{\text { l Total } l} \times$ Entrophy $($ Paling Diminati $)$ 
Gain ( Total Paling Diminati $)=$ $0,881290899-\left(\left(\frac{17}{30} *\right)+\left(\frac{22}{30} * 0,94566030\right)+\left(\frac{0}{30} * 0\right)+\left(\frac{0}{30} * 0\right)\right)$

Gain $($ Total Paling Diminati $)=0.042$

b. Implementasi Klasifikasi Algoritma C4.5 Menggunakan Rapid Miner

Berdasarkan padari Tabel diatas data yang diuji adalah 30 data kepuasan Pengunjung dan akan diuji menggunakan Tools rapid miner Sehinga didapatkan hasil klasifikasi kepuasan pengunjung. Hasil dari proses pertama maka akan mendapatkan hasil dalam ExampleSet yang dapat dilihat pada gambar 3 Hasilnya berupa informasi mengenai perbandingan dari kepuasan pengunjung pada data terhadap kepuasan oleh Tolss RapidMiner.

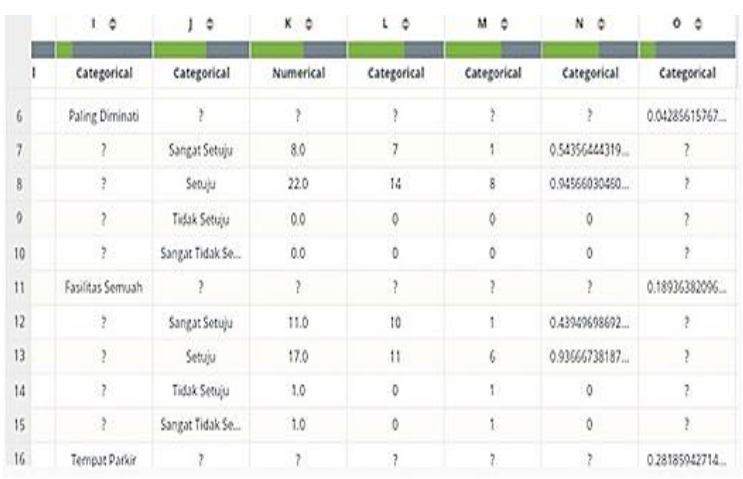

Gambar 1. Hasil ExampleSet Pada Tools RapidMiner

c. Hasil Pohon Keputusan Yang Dihasilkan

Setelah dilakukan perhitungan Algoritma c4.5 pada RapidMiner, Maka terbentuk pohon keputusan seperti gambar dibawah ini:

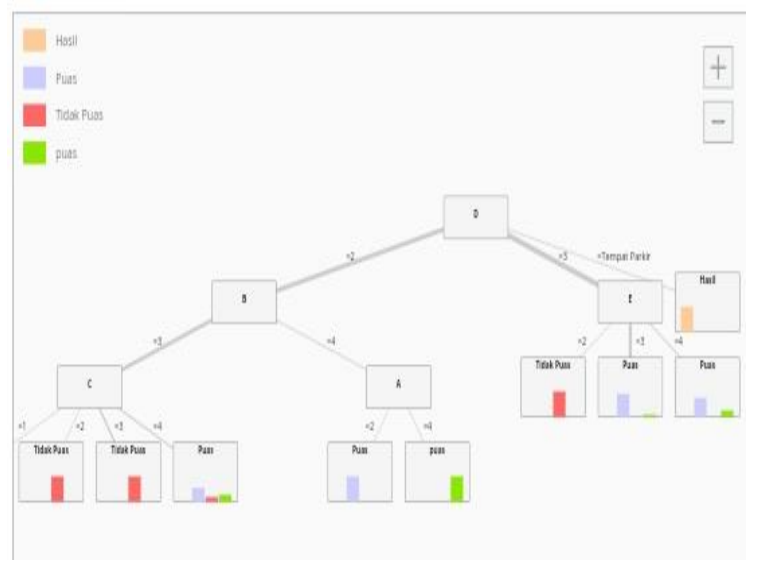

Gambar 2.Pohon Keputusan

\subsection{Hasil Penelitian}

Setelah melakukan perhitungan dari hasil kuesioner dan memudian dihitung,maka dari keseluruhan perhitungan tersebut diperoleh hasil sebagai berikut:

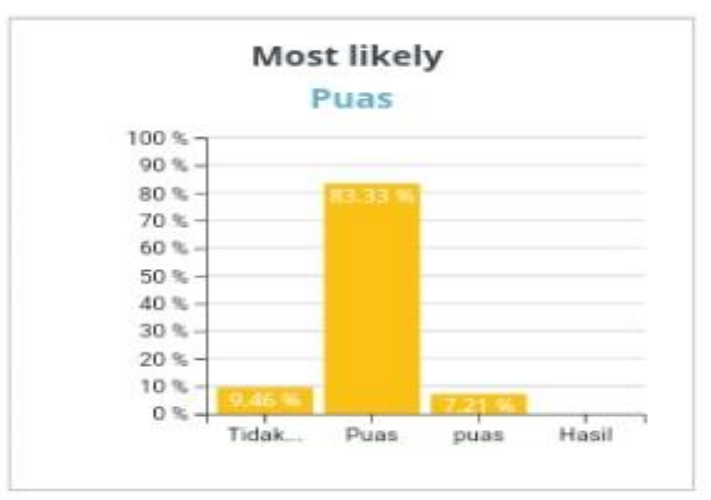

Gambar 3. Hasil

Hasil Perhitungan

Potensi dari penerapan data mining menggunakan metode Algoritma C4.5 dan tools Rapid Miner pada pengelolahaan data kepuasan pengunjung taman margasatwa menghasilkan potensi yang baik. Dibuktikan dengan hasil $83 \%$ puas terhadap fasilitas yang ada ditaman margasatwa

\section{KESIMPULAN}

Dari hasil penelitian yang telah dilakukan oleh peneliti, maka dapat disimpulkan bahwa kepuasan pengunjung taman margasatwa dapat diprediksi dan dievaluasi dengan memanfaatkan Algoritma C4.5 untuk memprediksi kepuasan pengunjung dengan traning yang diperoleh. Dari Penelitian diatas dapat disimpulkan bahwa 83\% pengunjung puas terhadap fasilitas ditaman margasatwa.

\section{REFERENSI}

Arifin, M. F., \& Fitrianah, D. (2018). Penerapan Algoritma Klasifikasi C4.5 Dalam Rekomendasi Penerimaan Mitra Penjualan Studi Kasus: PT Atria Artha Persada. InComTech, 8(2), 87-102. https://doi.org/10.22441/incomtech.v8i1.2198

Firmansyah, M., \& Aufany, R. (2016). Implementasi Metode Decision Tree Dan Algoritma C4.5 Untuk Klasifikasi Data Nasabah Bank. Infokam, XII(1), 1-12.

Han, J., Kamber, M., \& Pei, J. (2014). Data mining: Data mining concepts and techniques. In Proceedings - 2013 International Conference on Machine Intelligence Research and Advancement, ICMIRA 2013. morgan kaufmann. https://doi.org/10.1109/ICMIRA.2013.45

Junia, A., Studi, P., Informatika, T., Pelita, S., Jl, N., Iskandar, S., \& No, M. (2021). Implementasi Algoritma C4 . 5 Untuk Mengukur Tingkat Kepuasan BPJS Keternaga Kerjaan. 2(2), 1215. 
Mardi, Y. (2017). Data Mining: Klasifikasi Menggunakan Algoritma C4.5. Edik Informatika, 2(2), 213-219. https://doi.org/10.22202/ei.2016.v2i2.1465

Marhanah, S., \& Wahadi, W. H. (2016). Pengaruh Fasilitas Wisata Dan Kualitas Pelayanan Terhadap Kepuasan Pengunjung Di Taman Margasatwa Ragunan Jakarta. Jurnal Manajemen Resort Dan Leisure, 13(1). https://doi.org/10.17509/jurel.v13i1.2134

Novianti, B., Rismawan, T., \& Bahri, S. (2016). Implementasi Data Mining Dengan Algoritma C4.5 Untuk Penjurusan Siswa (Studi Kasus: Sma Negeri 1 Pontianak). Jurnal Coding, Sistem Komputer Untan, 04(3), 75-84.

Syarif Mayron Turnip, P. S. (2018). Analisis Pola Penyebaran Penyakit dengan. 03(479), 3-7. https://media.neliti.com/media/publications/28 2579-analisis-pola-penyebaran-penyakitdengan-767de6bd.pdf

Vogt, W. (2015). Proportional Stratified Random Sample. Dictionary of Statistics \& Methodology. https://doi.org/10.4135/9781412983907.n1534

Zelmiati Zelmiati, Waryono Waryono, Y. A. (2017). PENGARUH KUALITAS PELAYANAN TERHADAP KEPUASAN PENGUNJUNG DI OBJEK WISATA MINANG FANTASI KOTA PADANG PANJANG. E-Journal Home Economic and Tourism, 14. http://ejournal.unp.ac.id/index.php/jhet/article/ view/7180 